\title{
POLÍTICAS PÚBLICAS INOVADORAS DO ESTADO À MICRO E PEQUENAS EMPRESAS: OS PREGÕES PRESENCIAIS DO MUNICÍPIO DE ARAPONGAS - PR
}

\author{
INNOVATIVE PUBLIC POLICIES OF THE STATE TO MICRO AND SMALL \\ ENTERPRISES: THE PRESENT TRADING OF MUNICIPALITY OF ARAPONGAS - PR
}

Valdinei Juliano Pereira

Universidade Estadual de Londrina, PR, Brasil E-mail:valdineijuliano@hotmail.com

\section{Lisandro Pezzi Schmidt \\ Universidade Estadual do Centro-Oeste, PR, Brasil E-mail: lisandrops@hotmail.com}

\author{
Saulo Fabiano Amancio Vieira \\ Universidade Estadual de Londrina, PR, Brasil \\ E-mail: saulofav@gmail.com \\ Luís Miguel Luzio-dos-Santos \\ Universidade Estadual de Londrina, PR, Brasil \\ E-mail: Imig@uol.com.br
}

Recebido em: 13.12.2018 - Aceito em: 11.11.2019

DOI: http://dx.doi.org/10.5902/2526629236036

\section{RESUMO}

O presente artigo tem como proposta verificar o crescimento da participação de Micro e Pequenas Empresas (MPE) nos pregões de compras públicas, no órgão municipal de Arapongas - Paraná, a partir da Lei Complementar (LC) 147/14, de agosto de 2014, resultante da inovação da LC 123/06. Para tanto, foram levantados dados das licitações efetuadas, os tipos e a quantidade de empresas que participaram dos pregões, no intervalo entre 2012 a 2014 e 2014 a 2016, isto é, dois anos antes da promulgação da LC 147/14 e dois anos depois. A pesquisa realizada foi quantitativa, descritiva e documental, por meio de dados coletados no Portal da Transparência do Município, o que permitiu realizar a comparação entre os períodos. Concluiu-se que, a partir da inovação, através da LC 147/14, já no ano de 2014, houve um aumento considerável da participação e da contratação das MPE nas licitações governamentais do município, evidenciando a ruptura da participação hegemônica no mercado das empresas de médio e grande porte. 
Palavras-chave: Inovação; Compras Públicas; Licitação; Mercado; Gestão Pública.

\section{ABSTRACT}

The purpose of this article is to verify the growth in the participation of Micro and Small Companies / MPE in the public procurement sessions, in the Municipal Authority of Arapongas - Paraná, as of Complementary Law (LC) 147/14, August 2014 , resulting the innovation of LC 123/06. For this purpose, data on the bids made, the types and quantities of companies that took part in the trading sessions were collected between 2012 and 2014 and 2014 and 2016, ie two years before the enactment of LC 147/14 and two years later. The research was quantitative, descriptive and documentary, through data collected in the Transparency Portal of the Municipality, which allowed a comparison between the periods. It was concluded that, as a result of the innovation, through LC 147/14, in 2014, there was a considerable increase in the participation of MPEs in the municipal biddings of the municipality, evidencing the rupture of the hegemonic participation in the market of medium-sized companies and large size.

Keywords: Innovation; Public Procurement; Licitation; Marketplace; Public Administration.

\section{INTRODUÇÃO}

Tendo em vista o debate existente sobre as funções do Estado em relação ao mercado, bem como os seus limites de atuação, é indiscutível que a intervenção desse ator na economia desencadeie um impacto considerável, tanto positivo como negativo, ao crescimento econômico.

O mercado de aquisições públicas pelos órgãos do governo, sejam eles de ordem federal, estadual ou municipal, torna-se um formidável instrumento de intervenção econômica. De acordo com o Serviço Brasileiro de Apoio às Micro e Pequenas Empresas (SEBRAE) (2011), as compras governamentais impulsionam a economia, anualmente, em quatrocentos bilhões de reais, considerando as compras de todos os entes em conjunto com os órgãos públicos.

Em contrapartida, os gastos informados pelo SEBRAE (2011) sinalizam que as compras realizadas pelos entes da federação apresentam uma participação desigual entre os portes das empresas. Haja visto que, no ano de $2011,1 \%$ da 
participação das empresas em compras públicas eram de grande e médio porte, as quais participavam com um índice de $80 \%$ nessas aquisições. Em contraposição, às Micro e Pequenas Empresas (MPE) correspondiam, no mesmo ano, 99\% dos estabelecimentos comerciais, possuindo uma parcela de apenas $20 \%$ das compras públicas do Governo (SEBRAE, 2011).

De acordo com a definição trazida pela Lei Geral das MPEs (Lei n 123/2006), as Microempresas são aquelas que possuem faturamento anual de, no máximo, $\mathrm{R} \$$ 240 mil por ano e as Pequenas Empresas limitam seu faturamento de $\mathrm{R} \$ 240.000,01$ a $\mathrm{R} \$ 2,4$ milhões anualmente para serem consideradas com esse porte.

O Serviço Brasileiro de Apoio às Micro e Pequenas Empresas (SEBRAE, 2015) adota a definição de Microempresas como aquelas que empregam até 9 pessoas, no caso de comércio e serviços, e até 19 pessoas, no caso de setores industriais ou de construção. Enquanto as Pequenas Empresas são definidas como as que empregam entre 10 a 49 pessoas referente a comércio e serviços e, no caso de indústria e empresas de construção, empregam de 20 a 99 pessoas.

A disparidade quanto a participação de empresas de grande e médio porte e de Micro e Pequenas Empresas poderia acarretar a formação de oligopólios e de cartéis que impactariam diretamente no aumento dos gastos e/ou diminuição da qualidade dos bens e serviços contratados pelos entes da Administração Pública. Ainda poderia resultar em uma insatisfação da função de equilíbrio pelo Estado brasileiro, considerando que em 2013, as MPEs possuíam mais da metade dos empregos de forma legal em estabelecimentos privados e não agrícolas do país (SEBRAE, 2015).

Conhecendo a importância e o impacto das MPEs no cenário econômico nacional, os idealizadores da Carta Magna de 1988 determinaram o tratamento diferenciado para essas empresas nos art. 146, inciso III, alínea "d", art. 170, inciso IX e art. 179. Além disso, ao encontro dessa proposição de inovação e acesso ao mercado, encontram-se vinculados ao conjunto 17 objetivos de desenvolvimento sustentável e 169 metas traçadas pela Organização das Nações Unidas (ONU), os quais intencionam a implementação da Agenda 2030 em áreas de importância crucial para a humanidade e para o mundo nos próximos 15 anos. Assim, destaca-se a meta 2, que se enquadra no desenvolvimento da ação do governo, proporcionando privilégios às empresas menos favorecidas, definida pelo nono objetivo, e que busca

Promover a industrialização inclusiva e sustentável e, até 2030, aumentar significativamente a participação da indústria no emprego e no produto interno bruto, de acordo com as circunstâncias nacionais, e dobrar sua participação nos países de menor desenvolvimento relativo (ONU BRASIL, 2015). 
Não obstante, apenas no ano de 2006, com a regulamentação por meio da Lei Complementar (LC) 123/2006, passaram a surgir efeitos para as MPEs. A regulamentação trouxe a inovação na ordem jurídica ao estender as contratações públicas e despender tratamento diferenciado aos pequenos negócios, objetivando promover o desenvolvimento social e econômico no âmbito regional e local. Consequentemente, a eficiência nas aplicações das ações de políticas públicas foi ampliada, além de ter implantado também o regime diferenciado de tributação mais benéfico às MPEs.

Tendo o mesmo entendimento, a Lei Federal n. ${ }^{\circ}$ 12.349, de 15 de dezembro de 2010, inovou com a alteração do artigo $3^{\circ}$ da Lei de Licitações n. ${ }^{\circ} 8.666 / 1993$, incrementando a promoção do desenvolvimento nacional sustentável entre as finalidades da licitação.

Levando-se em consideração as desigualdades observadas entre as MPEs e as empresas de médio e grande porte, na arena de compras públicas, a problemática que norteou o presente estudo foi as inovações trazidas em favor das MPEs. Também buscou-se analisar se houve ou não resultado de forma efetiva no aumento da contratação para as aquisições governamentais.

Nesse sentido, a fim de verificar os resultados do cenário apresentado, foram analisados os pregões presenciais realizados no município de Arapongas (PR) no intervalo entre 2012 e 2016, no período de dois anos, antes da data da promulgação da Lei Complementar n. ${ }^{\circ}$ 147/2014, ou seja, em 7 de agosto de 2014 , e os dois anos posteriores. A representatividade das compras públicas no desenvolvimento sustentável foi verificada a partir do conceito do Triple Bottom Line, o tripé da sustentabilidade, idealizado por John Elkington (2004).

No intuito de alcançar os objetivos, este artigo está estruturado em cinco seções, sendo a primeira, a introdução, que apresenta a problemática, a justificativa e o objetivo proposto. A segunda aborda o referencial teórico, contemplando as teorias sobre as aquisições públicas, o desenvolvimento sustentável, a inovação e a pesquisa quantitativa, especificando-se a comparação entre os períodos. $\mathrm{Na}$ seção seguinte, apresenta-se a metodologia de pesquisa. Na quarta, os resultados da pesquisa empírica. E, finalizando, apresentam-se a conclusão e as considerações finais.

Entende-se que o presente trabalho possa contribuir para os gestores públicos, para a academia, para os empresários e afins, tendo em vista que o conteúdo permite a atualização dos referenciais pesquisados, servindo, portanto, de parâmetro para a tomada de decisões. 


\title{
2. REFERENCIAL TEÓRICO
}

\subsection{Inovação como ação do governo ao mercado}

Para a economia, o setor público, ao longo dos anos, tem-se expandido de forma significativa. Muitas ações governamentais corroboram de forma estratégica para regular as relações econômicas, suprir as necessidades da população com variados bens e serviços públicos, entre outras ações. Nesse sentido, a inovação no setor público pode ser considerada estratégica, a partir das ações do Estado, que refletem maior eficiência na sua atividade ao condicionar ganhos importantes para a sociedade. Porém, esse dinamismo das inovações do setor tem trazido poucas contribuições para a academia, principalmente por possuir uma reflexão sobre o dinamismo da inovação de maneira universal, na qual fortemente existe a presença privatista, que olha apenas para a geração de lucros e para a geração de estruturas mercantis de caráter schumpeteriano.

Schumpeter (1982) tipifica a inovação em: novo produto; novo mercado; nova fonte de matérias-primas; nova organização e novo processo de produção, que "[...] pode consistir também em nova maneira de manejar comercialmente uma mercadoria" (Schumpeter, 1982, p. 76). Pelo Manual de Oslo (1997), compreende-se inovação como:

\begin{abstract}
A implementação de um produto (bem ou serviço) novo ou significativamente meIhorado, ou um processo, ou um novo método de marketing, ou um novo método organizacional nas práticas de negócios, na organização do local de trabalho ou nas relações externas à utilização de produto (bem ou serviço) novo ou com melhoria significativa ou processo, método de marketing, ou um novo método organizacional nas práticas de negócio, na organização local de trabalho ou nas relações externas (OCDE, 1997, p. 55).
\end{abstract}

Percebe-se que, quando se muda o foco para o setor público, a lógica é diferente da aplicada pelo privado, pois no privado se visa o lucro e no público busca-se a eficiência, o que torna a discussão sobre a inovação nesse setor mais complexa. Para Nelson e Yates (1978), a diferença existente entre os setores público e privado é devido ao público possuir elementos menos diretos e objetivos do que a inovação existente no setor privado, na qual prevalece a busca pelo lucro.

É compreensível o caráter peculiar no setor público, pois em uma sociedade contemporânea, o papel do Estado é amplo, atuando como agente indutor e facilitador da atividade privada. O Estado é quem formula leis, políticas e as próprias 
entidades públicas, o que culmina no desenvolvimento das atividades do setor privado. Ele não atua apenas nos setores típicos de ação pública, mas também naquelas áreas de caráter social, além de áreas estratégicas e importantes para a atividade de cunho econômico pelo país. Sendo assim, o Estado pode ser considerado responsável pela inovação.

Portanto, é importante conceituar o que vem a ser a inovação para o setor público. De acordo com Halvorsen (2005), o conceito precisa ser entendido com uma ampla visão que abrange as seguintes tipologias: inovação de serviço; inovação de processo; inovação administrativa e organizacional; inovação do sistema e inovação de concepção e mudança radical de racionalidade. Dessa forma, os setores que possuem empresas públicas, aquecendo o mercado com empresas privadas, tendem a ser mais inovadores do que os setores em que a atividade do Estado é isolada.

\subsection{As formas inovadoras do Estado como instrumentos do desenvol- vimento nacional sustentável das MPEs}

De acordo com Silva (2014), o desenvolvimento sustentável pode ser analisado, por meio da convergência das perspectivas social, econômica, cultural e ecológica, no intuito de estabelecer o equilíbrio entre a satisfação das necessidades presentes, o planejamento e a conservação dos recursos futuros pela sociedade. $O$ autor também verifica que existem diversas noções de sustentabilidade conhecidas, porém, nesse caso, é melhor que essas noções sejam compreendidas através do conceito da Triple Bottom Line, ou seja, tripé da sustentabilidade, desenvolvido por John Elkinhton, em meados dos anos de 1990 (Silva, 2014).

Essa definição também é conhecida como $3 \mathrm{P}$ (People, Planet and Profit) que, para o desenvolvimento sustentável, é necessário considerar as seguintes dimensões: 1) People se refere ao tratamento pela empresa ao capital humano, compreendido como a contribuição social por meio da garantia de condições dignas de trabalho, dos direitos e dos benefícios a seus colaboradores, de forma direta e indireta, ocasionando uma mudança de sentido em suas famílias e comunidades; 2) Planet se refere ao capital natural, preservado pelas organizações ao adotarem medidas em favor da eficiência ecológica e ambiental em seus processos produtivos, inovando com soluções mais limpas e seguras para o meio ambiente, diminuindo o impacto ambiental e externalidades negativas que vierem a causar em sua atividade econômica, e 3) Profit refere-se ao lucro ou resultado econômico positivo obtido por meio do desempenho de sua atividade econômica (Silva, 2014). 
Ainda é citado por Silva (2014) que a sustentabilidade financeira pode ser considerada como a capacidade de o empreendedor cobrir seus custos operacionais, de transação e ter a oportunidade de permanecer ativo no mercado, em longo prazo, bem como é definido por Dum, Arbuckle e Parada (1998). Nesse viés, pode-se compreender que o desenvolvimento sustentável financeiro não é unicamente contemplado pelo resultado financeiro positivo do empreendimento, mas também pela capacidade da atividade comercial (negócio) em se manter num mercado cada vez mais dinâmico e competitivo.

A ferramenta de aquisição dos órgãos públicos brasileiros é regida pela Lei Geral 8.666/93 - cuja evidência está além do desenvolvimento econômico, por meio das demandas por bens e serviços, o que prioriza também o desenvolvimento sustentável, contida no artigo $3^{\circ}$ da referida Lei. Santana (2014, p. 21) argumenta que 0 art. $3^{\circ}$ passou a imantar inúmeros valores e princípios constitucionais que, no resumo prático, induzem e permitem a realização de várias políticas públicas a partir do poder de compra governamental.

Ao analisar as compras públicas realizadas no Brasil, pode-se enquadrá-las como um exemplo empírico de aplicação da teoria da Triple Botton Line. Nessa concepção, o Estado, por meio dessa medida, utiliza seu poder de aquisição com a finalidade de fomentar e desenvolver a economia pelo artifício legal das contratações de empresas de diversos setores do mercado, possibilitando o surgimento e a manutenção de níveis de emprego e o aquecimento do mercado local e regional. Com o crescimento da demanda, por meio das contratações realizadas pela Administração Pública, suas aquisições irão além de apenas suprir os bens necessários para o seu funcionamento. O destino dos recursos públicos poderá estimular o crescimento de grupos ou segmentos da sociedade considerados vulneráveis ou estratégicos para o desenvolvimento regional, sendo essa uma das peculiaridades da função estabilizadora do Estado (Arantes, 2006).

A expressão "uso do poder de compra" é relatada por Silva (2008) como uma verdadeira representação de poder, devido à disponibilidade de recursos pelo Estado. Isso Ihe confere a possibilidade de induzir comportamentos específicos em terceiros, objetivando resultados que ultrapassam o propósito de apenas suprir as necessidades da Administração Pública.

A promulgação do Estatuto das MPEs - Lei Complementar 123/06 -, pode ser considerada um exemplo dessa indução estatal. Nesse estatuto, foram criados vários mecanismos jurídicos que conferem às MPEs consideráveis vantagens nas licitações públicas em relação às empresas de porte médio e grande. A Lei Complementar 123/06 está vigente desde 14 de dezembro de 2006. Porém, na 
Administração Pública Municipal, os benefícios licitatórios em favor dos pequenos negócios eram aplicados apenas a aqueles referentes ao impacto ficto nos lances e na concessão de prazo para a regularização da documentação de habilitação.

A referida Lei passou a ter maior efetividade, a partir de 07 de agosto de 2014, com a sanção da Lei Complementar 147 - LC 147/14, que modificou a LC 123/06, destacado por Santana (2014) como uma das principais modificações da Administração Pública, na qual realiza processos licitatórios, exclusivos para as MPE em seus itens de até $R \$ 80$ mil. Assim, a licitação é disputada nesses moldes, ou seja, apenas por empresas de porte homogêneo para os itens que não ultrapassem o limite mencionado. Em comparação à legislação anterior a essa modificação, o benefício era facultativo e considerado superior aos $\mathrm{R} \$ 80$ mil, valor global do certame e não dos itens.

Sobre esse tema é importante registrar que o município de Arapongas começou a aplicar essa exclusividade nas contratações, a partir da promulgação da Lei Complementar 147/14 em que, dessa vez, afastou o teor facultativo e inseriu a obrigatoriedade da aplicação dos privilégios destinados às MPEs. Também houve alterações na LC 147/14, como a reserva de cota de até $25 \%$ do objeto do item para a disputa exclusiva entre MPEs, em se tratando de bens divisíveis. Nessas situações, é obrigatório que a Administração reserve parte da quantidade do objeto licitado em até $25 \%$ para as MPEs. Essa ação possibilita que esses pequenos negócios concorram aos $75 \%$ do objeto restante, mas disputando de forma igualitária com os demais tipos de empresa.

Santana (2014), por sua vez, menciona que não houve alteração da LC 123/06 no sentido de se tornar obrigatória a subcontratação de pequenos negócios para serviços e obras, por empresas vencedoras de certames. Não houve exigências, por parte da Administração Pública, no sentido de que as empresas vencedoras, classificadas como do tipo médio e de grande porte, sejam obrigadas a subcontratar MPEs para executar parcela do serviço ou da obra.

A LC 147/14 trouxe outras inovações como aponta Santana (2014): 1) a criação da preferência de contratação de MPE, no caso de dispensa de licitação em razão do valor; 2) a ampliação do prazo de dois dias para cinco dias úteis, no caso da MPE usufruir do benefício posteriormente e poder regularizar as pendências nos documentos de regularidade fiscal dentro do prazo legal; e 3) a criação da possibilidade de contratação de MPEs locais e regionais com valores até $10 \%$ acima da melhor proposta ofertada. 
No âmbito municipal de Arapongas, tais benefícios foram regulamentados pela Lei Municipal n. ${ }^{\circ}$ 4.422/2015 vigente a partir de 04 de novembro de 2015. Nesse ínterim, as inovações trazidas pela LC 147/14, em prol das MPEs, parecem ser promissoras para o fomento dos pequenos negócios, quanto para a convergência das aquisições pelo Estado e em prol do desenvolvimento sustentável. Esse princípio foi inserido no artigo $3^{\circ}$ da Lei 8.666/93, que diz:

[...] lembra aos aplicadores desta que, inclusive nas aquisições públicas, se deve utilizar de práticas que fomentem o crescimento do País, o que se consegue com atos de estímulo à indústria, ao comércio, ao emprego formal, ao desenvolvimento tecnológico e científico (Santana \& Andrade, 2011, p. 42).

Conforme o exposto, a LC 147/14 assegurou vantagens consideráveis para as MPEs, fortalecendo sua ação perante o mercado, não só no âmbito privado, mas preferencialmente no âmbito público, o qual privilegia de modo diferenciado suas contratações.

\section{MÉTODO DE PESQUISA}

Para alcançar os objetivos propostos, o presente trabalho se classifica como uma pesquisa de abordagem quantitativa, descritiva e documental com caráter exploratório. Caracteriza-se como o método misto, conforme Creswell e Plano Clark (2011), constituído pela abordagem quantitativa e qualitativa. Considerando que a pesquisa descritiva permite: 1) estudar o nível de atendimento dos órgãos públicos de uma comunidade; 2) possibilitar que se descubra a existência de associações entre variáveis; e 3) realizar uma observação sistemática dos dados (Gil, 2002).

A pesquisa tem um enfoque quantitativo, definido pela objetividade que as análises dos dados requerem. Pois, segundo Fonseca (2002), a realidade só pode ser compreendida com base na análise de dados brutos, recolhidos com o auxílio de instrumentos padronizados e neutros que é precisamente a fonte da qual os dados foram obtidos. A pesquisa se processa através de fatos sucessivos da realidade, fornecendo contribuições para uma intervenção no real.

Foi realizada uma pesquisa documental de análise de dados quantitativos, com a informação localizada em arquivos públicos, possuindo como parâmetro o sistema de compras do governo do Brasil e os aspectos relacionados à Lei Complementar $n .^{\circ} 123 / 06$, implementada a partir de dezembro de 2006 e inovada por meio da Lei Complementar n. ${ }^{\circ}$ 147/14. De acordo com Gil (2002, p. 62), a pes- 
quisa documental apresenta algumas vantagens por ser "fonte rica e estável de dados, principalmente pela possibilidade da leitura aprofundada das fontes".

Os dados dos tipos secundários foram coletados no Portal da Transparência do Município de Arapongas (PR). Organizou-se um banco de dados com variáveis para este estudo, com a quantidade de pregões presenciais, realizados pelo ente, entre o período de agosto de 2012 até agosto de 2016, abrangendo os Editais, as Atas e os Contratos encontrados no Portal da Transparência.

\footnotetext{
Como em boa parte dos casos os documentos a serem utilizados na pesquisa não receberam nenhum tratamento analítico, torna-se necessária a análise de seus dados, que deve ser realizada em observância aos objetivos e ao plano da pesquisa e pode exigir, em alguns casos, o uso de técnicas sofisticadas (Gil, 2002, p. 88).
}

Para a análise quantitativa, foram comparados os resultados de cada período da pesquisa, em forma de tabelas com uma ordenação lógica, o que permitiu um entendimento sistemático e uma descrição precisa dos fenômenos que aconteceram na linha do tempo analisada.

Justifica-se o período da pesquisa, uma vez que a LC 123/06 foi modificada por meio da LC 147/14 em agosto de 2014, sendo as licitações com as aplicações dos benefícios trazidos a partir da promulgação da alteração da LC 123/06. Dessa forma, os anos analisados anteriores a 2014, desde agosto de 2012, são necessários para inferir se houve uma mudança significativa, tomando o período referencial desde a inovação da Lei (agosto de 2014) até o cumprimento de dois anos no calendário (agosto de 2016). Sendo assim, o último período, o posterior a reforma, é o que será considerado para observar se houve ou não modificações na presença de MPE nos pregões. Foram contemplados neste estudo 693 pregões, levando-se em consideração o intervalo de tempo acima estipulado, sendo 384 no período anterior à reforma e 309 no período posterior.

O órgão municipal, Arapongas (Paraná), foi escolhido devido à facilidade de acesso aos dados, assim como aos documentos necessários e a verificação, in loco, de algumas informações que seriam entendidas como divergentes.

\section{APRESENTAÇÃO E DISCUSSÃO DOS RESULTADOS}

A fim de identificar se houve evidências no crescimento da participação de MPE nos pregões de licitação no município de Arapongas, foi realizada uma análise exploratória, a partir dos dados obtidos sobre essas participações, no Portal de 
Transparência do Município. Utilizando-se da análise comparativa, demonstra-se que houve evidências no aumento do número de MPE nos pregões presenciais, no período de 2014 a 2016, após a inovação constante na LC 147/14. Os resultados da pesquisa são discriminados na Tabela 1 e representados na Figura 1, conforme relacionados abaixo.

Tabela 1 Quantidade de Pregões Presenciais Realizados em Arapongas

\begin{tabular}{c|c|c|c|c|c}
\hline Período & $\begin{array}{c}\text { Quantidade } \\
\text { de Licitações } \\
\text { realizadas }\end{array}$ & $\begin{array}{c}\text { Participação } \\
- \text { MPE }\end{array}$ & $\begin{array}{c}\text { Partici- } \\
\text { pação } \\
- \text { Outras } \\
\text { (Médio e } \\
\text { Grande } \\
\text { Porte) }\end{array}$ & $\begin{array}{c}\text { Contrata- } \\
\text { ção - MPE }\end{array}$ & $\begin{array}{c}\text { Contrata- } \\
\text { ção - Outras } \\
\text { (Médio e } \\
\text { Grande Por- } \\
\text { te) }\end{array}$ \\
\hline 2012 a 2014 & 384 & 209 & 107 & 176 & 80 \\
\hline 2014 a 2016 & 309 & 1064 & 268 & 813 & 69 \\
\hline Total & 693 & 1273 & 375 & 989 & 149 \\
\hline
\end{tabular}

Nota. Portal da Transparência do Município de Arapongas (2012-2016).

Figura 1 Participação e contratação das MPEs em Arapongas

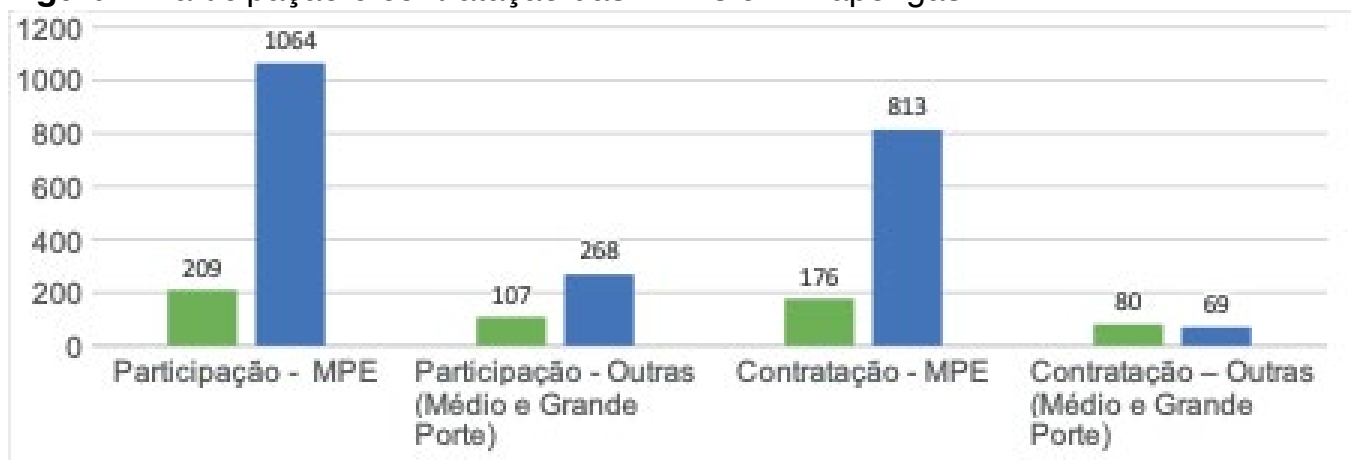

= 2012 a $2014=2014$ a 2016

Nota. Portal da Transparência do Município de Arapongas (2012-2016).

Observa-se, portanto, um aumento considerável da participação das MPEs, tanto regionais quanto locais, nas licitações governamentais em Arapongas, no período após a inovação proposta pela Lei Complementar 147/14 sobre a LC 123/06. Conforme a análise de dados obtidos a partir do Portal da Transparência do Município, um dos possíveis motivos do incremento dessa participação foi a implantação da referida legislação no município.

O que se nota é a estabilização da participação das MPEs pela Lei promulgada e aplicada em 2014, que, ao ser implementada pelo município, permitiu o aumento desses tipos de empresas nos pregões e, por conseguinte, sua contratação. Isso possibilitou benefícios num setor em crescimento que vinha sendo prejudicado 
pelo próprio Estado, por intermédio de uma Lei que, em seu escopo, fomentou certa "injustiça" ao não prever um descompasso entre a hegemonia das médias e grandes empresas e as MPEs nos pregões de licitações do período anterior à inovação.

Um requisito relevante a ser considerado sob o tripé do desenvolvimento sustentável, e que provavelmente impulsionou o aumento da participação de MPE nos pregões, foi o obtido por intermédio da inovação e da Lei Municipal n. ${ }^{\circ} 4.422 / 2015$, vigente a partir de 04 de novembro de 2015. Essa lei concedeu privilégios às MPEs locais, ao serem aprovadas mesmo apresentando orçamentos que estivessem $10 \%$ acima dos propostos por MPE de outros municípios ou Estados. A inovação permitiu o aumento do crescimento de MPE nos processos licitatórios, considerado um segmento vulnerável no interior do sistema capitalista vigente, além de um aumento potencial da estratégia estatal, por meio da Lei Municipal n. ${ }^{\circ}$ 4.422/2015.

São notáveis os avanços da Administração Pública de Arapongas, ao inovar, por meio de Leis, as condições do ingresso das MPEs em pregões, diminuindo a desigualdade e concedendo oportunidades a um segmento vulnerável e achatado pela hegemonia de empresas de médio e grande porte na participação em licitações. Segundo Borinelli, Capelari e Gonçalves (2015, p. 143).

Nas últimas décadas, mesmo sob fortes restrições e condições desfavoráveis, movimentos socioambientais e segmentos do Estado e do setor privado têm conquistado importantes avanços na reivindicação de direitos de minorias e no reconhecimento de riscos sociais e ambientais, geralmente invisíveis às avaliações e interesses tecnocráticos e tradicionais.

Contudo, essa conquista deve ser ampliada, pois

[...] os desafios teóricos e políticos são enormes, exigindo que se continue a apostar no debate autônomo, interdisciplinar e inclusivo sobre as ameaças, incertezas e alternativas que se apresentam na realidade brasileira e mundial (Borinelli, Capelari, \& Gonçalves, 2015, p. 143).

A relação sustentável, proposta pelo Triple Bottom Line, também foi viabilizada por essa inovação (LC 147/14), ao se contratar MPEs locais e contribuir para o desenvolvimento sustentável da região. Essa valorização das MPEs locais pode ter reduzido custos e também ter possibilitado o aumento da supervisão do Estado no fornecimento, pelo fato dessas MPEs estarem mais próximas ao núcleo utilizador de seus produtos e/ou serviços.

A proximidade também pode permitir que o Estado elabore novas políticas públicas mais eficientes, a partir do "uso de poder de compra" governamental, além de poder melhorar a supervisão das condições dos trabalhadores dessas MPEs, ao operacionalizarem os processos de fornecimento. 


\section{CONSIDERAÇÕES FINAIS}

Resgatando o objetivo inicial do trabalho em verificar se houve aumento da participação e posterior contratação das MPEs nas aquisições governamentais por meio da inovação trazida pela LC 147/14, resultou-se de forma positiva a existência de um aumento significativo da participação desse tipo de empresa nos pregões presenciais do município de Arapongas. Um dos possíveis motivos para o incremento da participação foi a implantação da referida legislação, fortalecendo a eficiência das políticas públicas adotadas pelo governo e aplicadas pelo órgão, o que refletiu de maneira significante ao objetivo traçado pela Organização das Nações Unidas (ONU).

Com relação aos aspectos teóricos, admite-se que a abordagem sobre inovação pode ser utilizada de forma satisfatória para entender o desenvolvimento sustentável nas aquisições públicas, a fim de privilegiar às empresas menos favorecidas, proporcionando seu crescimento de acordo com o conceito de Triple Bottom Line.

Outro problema que poderia ser pesquisado é justamente sobre o aumento excepcional de MPE na participação de licitações e da contratação dessas empresas, que seria investigar os reais motivos da abertura dessas MPEs. O que se percebeu foi que a partir de questionamentos realizados, durante a busca por dados no portal, muitas das empresas que se candidataram foram recém-abertas e ou abertas por volta do ano de 2014.

A sugestão é verificar se essas empresas foram oportunidades de negócios ou se são derivações de empresas de médio ou grande porte almejando participar dos processos licitatórios para MPE e usufruindo dos benefícios conquistados por essa categoria. Considera-se que o desenvolvimento de pesquisas, nesse sentido, seja de extrema importância, a fim de se esclarecer a verdadeira razão do surgimento de novas MPEs, a partir do ano de 2014. Pois, sabe-se que o Brasil apresenta um histórico de formação política patrimonialista, o que dificultou e dificulta o entendimento da diferença que há entre o público e o privado e o predomínio do interesse particular sobre o coletivo, ao longo da formação do país (Hollanda, 1995).

Novas pesquisas poderão ser realizadas, a fim de se contabilizar a eficiência ecológica a partir da Administração Pública, devido à proximidade das MPEs dos locais solicitantes de seus serviços e/ou produtos e ao reduzirem, por exemplo, custos com deslocamentos, como o consumo de combustível e a deterioração de veículos, assim como a sobrecarga de horas de serviço e outros riscos que incidem nos trabalhadores ao serem deslocados por grandes distâncias entre o local de moradia e o de trabalho. Outro fator que poderia ser mensurado, quanto 
às melhorias da qualidade de vida, é a averiguação constante, sob a legislação pertinente pelo Estado, das condições dos trabalhadores das MPEs contratadas ao realizarem o fornecimento de seus serviços e/ou produtos, assim como a qualidade de vida da comunidade local.

\section{REFERÊNCIAS}

Arantes, R. S. (2006, novembro). O uso do poder de compra do Estado para a geração de emprego e renda e o desenvolvimento local. In: XI Congreso Internacional Del Clad sobre La Reforma Del Estado Y De La Admnistración Pública, Ciudad de Guatemala, Guatemala.

Arapongas (Município). Lei $n^{\circ} 4.422$, de 04 de Novembro de 1995. Recuperado de http://www.arapongas.pr.gov.br.

Borinelli, B., Capelari, M. G.M., \& Gonçalves, D. M. (2015) Riscos socioambientais e cultura política: algumas considerações sobre o caso brasileiro. Interações - Revista Internacional de Desenvolvimento Local, Campo Grande, 16(1), 143-154.

Brasil. (1988). Constituição da República Federativa do Brasil, de 05 de outubro de 1988. Diário Oficial [da] República Federativa do Brasil, Brasília, DF, 5 out. 1988. Recuperado de http://www.planalto.gov.br/ccivil_03/Constituicao/ Constituicao.htm.

Brasil. (1993). Lei $n^{\circ}$ 8.666, de 21 de junho de 1993. Recuperado de http://www. planalto.gov.br

Brasil. (2006). Lei Complementar $n^{\circ} 123$, de 14 de dezembro de 2006. Recuperado de http://www.planalto.gov.br.

Creswll, J. W., \& Plano Clark, V. L. (2011). Designing and conducting mixed methods research (2 ed.). Los Angeles: SAGE Publications.

Dum, E. G., Arbuckle, J. G. Jr., \& Prada, M. R. C. (1998). Extending microfinance approaches into the agricultural sector: a review of key concepts. Columbia: University of Missouri.

Elkington, J. (2004). Enter the triple bottom line. In: Henriques, A., \& Richardson, J (Eds.), The triple bottom line: Does it all add up (pp. 1-16). Routlegde.

Fonseca, J. J. S. (2002). Metodologia da pesquisa científica. Fortaleza: UEC.

Gil, A. C. (2002). Como Elaborar Projetos de Pesquisa (4 ed.). São Paulo: Atlas.

Halvorsen, T. (2005). On innovation in the public sector. In: Halvorsen, T., Hauknes, J., Miles, I., \& Roste, R. On the differences between public and private sector innovation. NIFU STEP: Oslo.

Hollanda, S. B. de. (1995). Raízes do Brasil. São Paulo: Companhia das Letras. 
Valdinei Juliano Pereira, Lisandro Pezzi Schmidt,

Nelson, R., \& Yates. D. (1978). Innovation and Implementation in Public Organizations. Lexington Books: New York.

Organização para Cooperação e Desenvolvimento Econômico. (1997). Manual de Oslo: diretrizes para coleta e interpretação de dados sobre inovação (3 ed.). Tradução de Flávia Gouveia. Recuperado de https://www.finep.gov.br/ images/apoio-e-financiamento/manualoslo.pdf

Organização das Nações Unidas Brasil. (2015). 17 objetivos para transformar 0 nosso mundo. Recuperado de https://nacoesunidas.org/pos2015/.

Santana, J. E. Novo Estatuto da ME e EPP. Lei Complementar n 147 de 07 de agosto de 2014. (2014). Essencialidades e Orientações. Belo Horizonte: Ed. Fórum.

Santana, J. E., \& Andrade, F. As Alterações da Lei Geral de Licitações pela Lei $n^{\circ}$ 12.349, de 2010: Novos Paradigmas, Princípios e Desafios. (2001, Fevereiro/Março). Revista Síntese Licitações, Contratos e Convênios, 1.

Schumpeter, J. A. (1982). Teoria do desenvolvimento econômico: uma investigação sobre lucros, capital, crédito, juro e o ciclo econômico. São Paulo: Abril Cultural.

Serviço Brasileiro de Apoio às Micro e Pequenas Empresas. (2001, Novembro). Negócios com governos movimentam cerca de $\mathrm{R} \$ 400$ bi por ano. Revista Conhecer, 20, 16-19.

Serviço Brasileiro de Apoio às Micro e Pequenas Empresas. (2015). Anuário do trabalho na micro e pequena empresa: 2015. Departamento Intersindical de Estatística e Estudos Socioeconômicos [responsável pela elaboração da pesquisa, dos textos, tabelas, gráficos e mapas]. p. 27. Recuperado de http://www.pr.agenciasebrae.com.br.

Silva, E. P. (2008). O uso do Poder de Compra do Estado como Instrumento de Política Pública: A Lei no 123/2006, sua implementação (Tese de Mestrado). Fundação Getúlio Vargas, Rio de Janeiro.

Silva, W. A. C. (2014). Sustentabilidade Financeira Do Pequeno E Médio Varejista Do Segmento Supermercadista Na Região Metropolitana De Belo Horizonte (Tese de Mestrado). Unihorizontes, Minas Gerais. 